\title{
Transmitting cinema: Some proposals for our time
}

\author{
Núria Aidelman* and Laia Colell - Co-founders and directors of A Bao A Qu, \\ Barcelona, Spain
}

Translated by Maria Velez-Serna

\begin{abstract}
'Transmitting cinema: Some proposals for our time' was a conference that took place at Pompeu Fabra University in Barcelona on 13-14 July 2017, as part of the international European film education programme Moving Cinema. This report summarizes and reflects upon some of the discussions that took place at the conference-exploring some of the most resonant questions facing film education practitioners and cultural partners in diverse contexts across Europe - before going on to make a timely series of proposals for European film education in 2018.
\end{abstract}

Keywords: film education; youth; cultural engagement; auteur cinema; art education

\section{Context and framework}

'Transmitting cinema: Some proposals for our time' was a conference that took place at Pompeu Fabra University in Barcelona on 13-14 July 2017, within the framework of the international European film education programme Moving Cinema, with the collaboration of CinEd (European Cinema Education for Youth). As part of the conference, groups of film education practitioners, teachers, film-makers and other cultural professionals from across Europe gathered for a series of discussion sessions to explore together what we consider to be some of the most fundamental questions for film education in Europe in our time. These discussions were recorded, and later collated by the Moving Cinema team. This report will give a sense of the aims and scope of Moving Cinema's lively discussion sessions, before presenting some of the conclusions drawn. For full details of the conference, including a list of participants, see: www.movingcinema.eu/conference2017.

Moving Cinema is a programme conceived by $\mathrm{A} B$ ao $\mathrm{A} Q \mathrm{Qu}$, a non-profit cultural organization founded in Barcelona in 2004 and devoted to the conception and development of programmes linking art to schools, especially film education. At its inception in 2014, Moving Cinema had two motivations. On the one hand, A Bao A Qu had long been troubled by a question we frequently heard from our students when their time in Cinema en curs (the film pedagogy international programme we have been developing in schools since 2005, which is especially concerned with linking film viewings to creative practice) came to an end. That question was, now what? Or, to elaborate, now that we have discovered cinema, that we know we enjoy watching and making films, how do we stay connected to film? How can it continue to belong to us?

Our other motivation with Moving Cinema was to create an international network allowing us to explore these questions with film education practitioners elsewhere in Europe. The first Creative Europe Media call for audience development projects thus 
moved us to initiate collaboration and interchange with two main partners, Meno Avilys (Lithuania) and Os Filhos de Lumière (Portugal), to explore those questions. Later on, we opened up this partnership to the Centre for the Moving Image (Scotland), Kijufi (Germany), the Cinémathèque française (France) and the British Film Institute (UK).

Moving Cinema's principal aim is to build strong bonds between young people and film, to give them the tools to become autonomous spectators, and ultimately to bring forth active and sensitive viewers possessing the ability to enjoy diverse cinematic forms. The project focuses on European auteur cinema, both contemporary and historical. It favours films and film-makers that stand outside the mainstream but that can engage young people profoundly and intensely.

In its first three years (the school years 2014/15, 2015/16 and 2016/17), Moving Cinema explored five areas: (1) attendance at festivals and screenings; (2) young programmers; (3) filming on mobile devices, following cinematic reference points; (4) access to films on video on demand (VOD) platforms; and (5) Inside Cinema, an online platform making available materials documenting the creative process of films such as The 400 Blows (1959), Pierrot le fou (1965) and Estiu 1993 (2017), for anyone to analyse and explore.

These activities were analysed, reviewed and compared in order to arrive at strategies, proposals and methodologies that could be transferred to various contexts. The resources created by the project are openly available at www.movingcinema.eu, and are intended to be accessible to people, groups and institutions interested in film education anywhere in the world. We have also arranged training programmes, both in the countries of the partner organizations and in other European countries. Through these activities, Moving Cinema has been weaving together an important network of festivals, cinema venues and exhibition spaces, education centres and institutions working together to support film education among young people in Europe.

After three years of research and experimentation, in 2017 we established the 'Transmitting cinema: Some proposals for our time' conference in order to open up a space for exchange and shared reflection between professionals involved with the transmission of cinema and culture from 11 different European countries. We also strove to enhance participation by film-makers and teachers from the Cinema en curs team, as they are directly, deeply concerned in the matter. We also involved the real protagonists of our projects, namely the young people themselves. There is a full list of participants at the end of this article.

\section{Approach}

The title of the conference was inspired by Italo Calvino's Six Memos for the Next Millennium. In his prologue, Calvino (2016: 1) writes: 'My faith in the future of literature rests on the knowledge that there are things that only literature, with its particular capacities, can give us.' We can say the same about cinema: its future resides in its particularities, in what makes it unique and therefore indispensable.

The need for film education has been repeatedly acknowledged for many years. Several arguments have been posed from different perspectives. Our title, 'Transmitting cinema: Some proposals for our time', aimed to emphasize the urgent need for that pedagogy of cinema today, in our times. Furthermore, the title marked our intention not to centre the reflection that took place during the conference on the rehearsal of arguments about the need for film education. Instead, the aim was to offer methodologies, strategies and concrete ways to develop film education actions with a view to nurturing the discovery of film as an art form and creative practice, while 
helping this cinema find a place in young people's lives. The main goal of the sessions was therefore to create spaces for shared reflection in four specific areas: (1) the school as encounter and springboard; (2) young people's participation in cultural life; (3) the experience of creation; and (4) the bond with cinema auteurs.

During the two days of the conference, reflection upon each of these areas began with three 15-minute presentations from professionals in education, cinema and culture, and those directly involved with transmission of film and culture. Recordings of all these presentations can be seen on Moving Cinema's Vimeo page, links to which are included at the end of this article. Following these short papers, the combined conference assembly split into working groups to share practices, methods and strategies centred around the topics set for each discussion and around a given list of questions (see below) set by the conference organizers.

The conference concluded with a presentation by the film-maker Carla Simón, exploring the creative process for her recent film Estiu 1993 (Summer 1993, 2017), materials for which can be found via www.insidecinema.org (available from January 2019).

\section{The questions}

Over the two days of 'Transmitting cinema: Some proposals for our time', each working group of conference delegates received a list of questions formulated by the Moving Cinema team, which looked to open up reflection upon the key issues in the transmission of cinema to young people, such as:

- How can we create spaces for encounters with cinema at school?

- What can we do at school to connect young people with film beyond their school life?

-What should our criteria be in evaluating the usefulness of our actions or projects?

- What do we mean by 'cultural participation'?

- How can we encourage young people to take part in cultural events that are not specifically targeted at a young audience?

- How do we enable young people to become cultural agents (creators, disseminators, programmers and so on)?

- What sort of mediation is required for activities organized by young people?

- What do we expect from cultural institutions? And what can the managers of cultural institutions do for young spectators?

- How does the experience of creation contribute to deep learning about cinema?

- How can adults (teachers, film-makers, educators) support these processes?

- What logistical and organizational aspects are important in developing creative processes?

- How can we best organize film screenings for young people?

- What tools can we use to spark and facilitate dialogue immediately after the screening?

- What criteria do we consider in choosing the films we watch with students?

- What strategies and methods do we have to generate personal and profound connections between young people, films and auteurs?

\section{Summary of the discussions and reflections}

What follows is a summary of the reflections that took place across the many discussion groups organized over the two days of Moving Cinema's 'Transmitting cinema: Some 
proposals for our time' conference. In summarizing discussions, we have tried to include a sense of some of the different voices within the discussion, while also presenting our own conclusions as the organizers and directors of Moving Cinema.

\section{The school: A place for encounter}

An idea often repeated and acquiesced to throughout the discussion sessions of the conference was that of the fundamental role of the school as a place of encounter with a type of cinema that many children and young people will never have a chance to discover elsewhere. Many in the discussion groups felt that this is precisely why it is so important that film education programmes take place in state schools, so that they can reach all young people, across all socio-economic groups, particularly those further removed from cultural life. The school not only guarantees access to culture for the whole school-age population, but it can and should also offer ways to approach it.

In that sense, and also considering the context of educational institutions at a time of crisis and paradigm change, Marta Comas (Director for Innovation at the Consorci d'Educació de Barcelona, the institution responsible for the city's schools) posed this question: Are there some things that only the school can offer, due to its specific means? A first response, of course, from many of those involved in the discussions is precisely that the school as an institution is still necessary because it has the responsibility of putting knowledge and culture within the reach of the whole population, regardless of their background. Beyond this, the school must continue to be the space that makes possible true learning, understood to an extent as the opposite of curiosity. Curiosity is quickly sated, while knowledge, on the contrary, is built over time, requiring a systematic, sustained research process.

The school, where young people spend an average of ten thousand hours between the ages of 6 and 16 , is the space that enables this deep engagement with content, exhaustive analysis, comparisons, perseverance in the face of difficulty, and the search for new routes through the continually forking paths of knowledge. It was therefore felt by many discussion participants that the school must foster students who are able to go beyond the impulsive, repetitive 'like' button - sensitive and freethinking people, who find freedom in their ability to have their own criteria. Loris Magaluzzi (1920-94), founder of the Reggio Emilia pedagogical philosophy, previously summarized this in arguing that the school should be an ethical, aesthetic and political project all at once. This is the view that we at A Bao A Qu share when we bring cinema into schools as a transformative and cohesive element. Seen as an art, film opens up a different sensibility from that imposed by mass media; it addresses each person individually, it sparks reflection, and it leads to a discovery of film as a form of thought. It would seem to us that the school should be the place where we learn how to think, and also a place for beauty, for well-being and for contemplation. Taste, appreciation, sensibility and reflection are not innate, and the school is where they can be practised by everyone.

\section{Obstacles}

Bringing cinema into the school is not without difficulties. In most European countries, film is not part of the curriculum, nor does it have a defined space in the timetable. Introducing cinema, especially as a creative process (which many in our discussion groups felt can be most useful), often requires flexible schedules, a rupture with habitual order, and less compartmentalized working spaces. Another obstacle that surfaced in the experience of many of the conference delegates is the fear many 
classroom teachers have of introducing new methods, contents and processes that they do not fully understand themselves. It was found that this can very often generate great insecurity for teachers, and that it is therefore very important to communicate to teachers that one does not need to be a film expert in order to develop and take part in the projects: the teacher's role is as a guide and fellow traveller, facilitating and encouraging student learning. Finally, and especially in some countries or territories, many schools lack the minimum technical equipment (such as projectors and computers) and the funds to acquire it. This is likely to be an issue that can only be addressed by administrators, in order to provide adequate equipment.

Regarding the place of cinema in the curriculum and the timetable, some useful suggestions are:

- Produce a document outlining how cinema can be connected to other curriculum areas.

- Document systematically the activities carried out and the results obtained by the programme (although we must not forget that this documentation also requires considerable time and resources).

- On a structural level, there is a need to open lines of dialogue with the national authorities in countries where film education is still underprovided, to encourage them to consider film in the design of pedagogical programmes - this political approach is key to the expansion of the proposals.

\section{Opportunities}

Despite these difficulties, participants felt that the current moment is also one of great opportunities, particularly for programmes that can contribute to the renovation of teaching. Film pedagogy programmes challenge established structures (timetables, organization and so on), question habitual practices, and shift the roles and relationships between teachers and students, which is why they have much to contribute. The experiences of those in the discussion groups revealed that there are many pedagogic values that can arise from film education programmes:

- They favour interdisciplinarity, and link together a great number of different disciplines.

- They centre upon cinema as a tool for practising oral and written expression, image and text comprehension, and the ability to discuss and argue.

- They promote active learning, situating students as protagonists in their own learning, and letting students take the lead.

- They bring together many personal competencies: they develop attention, observation and conscientiousness; they demand decision-making, foster abilities to choose and discard; they ask participants to exercise individual and collective responsibility; they require processes of review and critique; they awaken aesthetic sensibility; they may provide spaces for cultural diversity.

- They nurture links and collaborations between school and the outside world.

- They situate the school as a centre for cultural redistribution and production, where students are not just receivers but also producers of knowledge.

- They promote cooperative work, dialogue and active listening.

- They are based on grounded learning, and therefore connect lived experience and knowledge.

- They enable deep reflection on emotions.

- They give way to pleasure, enjoyment and individual sensibility. 
- Film itself introduces a different sense of time, an alien rhythm to habitual school and social routines; it demands long process, waiting and reviewing as an organic part of creative processes.

Many participants in our discussion groups argued that film education's richness and role in students' integral formation create the need to establish qualitative evaluation mechanisms that can show the positive outcomes of film in school, and that can be translated into indicators to evaluate student learning - making these aspects measurable and demonstrable for institutions, public administration and other teachers, and for the students themselves. These qualitative indicators, prioritized by consensus by the participants, could be complemented with yet-to-be-defined quantitative markers. In that sense, we propose starting research projects leading to the new tools to systematize processes and projects. Meanwhile, we also underline the importance of personal, singular processes and projects. Some teachers have pointed out that a key part of evaluation entails revisiting after some time, for instance by contacting alumni. This may seem difficult to achieve at present, but we agree that it would be interesting to find ways to do it.

Another relevant conclusion from the discussions is that programmes that offer deep immersion in creative processes, and that bring in a film-maker or guest from outside the school system, are the most powerful in terms of their transformative potential for students, teachers and the school (see below: 'Bringing film-makers and other professionals into the school' and 'The experience of creation').

\section{Going beyond the school}

One of Moving Cinema's highest priorities is bringing film into young people's lives, even beyond the school - that is, in their spare time and also after they have left school. The point is not only to put film (and culture more broadly) within students' reach, but to let them go beyond the school, giving them tools to access film and cultural spaces autonomously. In other words, we need to build a solid bridge that young people can start crossing when they are at school, and that then allows them to keep visiting the other shore once they have left.

To achieve this, Moving Cinema has designed and delivered two strategies:

- Attending regular screenings at cinemas and festivals. Young people are advised to attend voluntarily according to their interests.

- Working with VOD platforms to enable young people to watch films at home, choose films according to their changing interests, choose when to watch and so on. This strategy has been particularly interesting in terms of young people's relationships with their families, as young people have become educators for their households, introducing them to film-makers and films, and leading dialogue.

In both cases, three elements seem to be key:

- The value of prescriptive roles. Teachers, film-makers, and other cultural mediators or disseminators play a prescriptive role. How does someone acquire a prescriptive role? The answer is simply, when other people consider they have it. A relationship of mutual trust is needed, as well as the acknowledgement of knowledge and expertise. Prescription is based on personalization, so it is necessary to know each person's tastes and preferences as much as possible.

- The opportunity that is opened up by the spaces created for students to share their impressions about films they watch outside school, so that they can also 
recommend films to each other, and little by little assume that prescriptive role for one another. Students can play a powerful role in the process of disseminating cinema among themselves. Besides, this reinforces the idea of cinema as a collective experience, and helps combat all sorts of prejudices against the moving image.

- Ultimately, it was posed that the role of institutions, facilities and festivals is key, and that these cultural bodies must actively open up to young people, to address them directly and enable easier access (see below: 'Cultural institutions').

\section{Teachers}

Many of those taking part in the discussion groups considered that the presence of film-makers and guests from outside the schools makes a difference to the depth and quality of film education. This does not mean that the teacher's role is less relevant - rather the opposite. Everyone, especially film-makers, mediators and cultural disseminators, realizes that teachers are the truly decisive figures. They are the ones who open their doors to film and get involved in projects; they ensure the pedagogic value of the process; they can give continuity to the actions proposed by the programmes. Insofar as we campaign to bring film into the school, we must first of all ensure the involvement of teachers.

One of the indispensable factors necessary to make this possible - and it is worth mentioning that it is mainly teachers themselves who requested this - is teacher training. Fanny Figueras, a teacher who has been introducing film in secondary school and baccalaureate, and engaging with Cinema en curs, Moving Cinema and CinEd, points out that the training provided by these programmes is particularly significant because it combines three features that should be part of any teacher training:

- Specific training, devoted, for instance, to film analysis, screenwriting, shooting and editing workshops.

- Classroom training applied to one's own practice. Sharing processes with a filmmaker and developing a joint project with students are especially relevant forms of learning because they take place in a real context and enable reflection on one's own teaching practice.

- Peer exchange - creating spaces to talk and exchange ideas and experiences with other teachers is an important source of ideas and resources.

Although training is indispensable, many participants felt that it is also necessary for teachers to change their perspective on their own condition or role. In general, the discussion groups were in agreement that we must conquer the fear of learning alongside the students, of discovering at the same time as them, and even learning from them. The teacher's role is that of fellow traveller and guide; some might even use the term 'curator', as the teacher selects content.

Further key aspects for teaching practice in these programmes that arose from the discussions are sharing your own passion, and fully trusting the students and avoiding any prejudices about what might be interesting to them or not, and about what they are able to comprehend. Finally, it is also the teacher's responsibility to find a balance between shared and personalized, collective and individual aspects. There must be group support alongside individual support for each of the students. We must realize that within the same group there may be different sensibilities and emotions, and these should be integrated, while respecting the individuality of each student. 
The teacher's role (like that of the film-maker or anyone involved with the transmission of culture) is often on the cusp between pushing and pulling. We have the responsibility of exerting some resistance in order to create new habits and an interest in the unknown. What we share is a real love of cinema: an honest, non-hierarchical love, which allows us to communicate from a position of sincerity.

\section{Bringing film-makers and other professionals into the school}

Among the 'Transmitting cinema' discussion participants, there was no doubt about the value of bringing film-makers and other guests into the school. Film-makers bring in their own intimate, profound and personal relationship to film, their unique view on art and on the world, a different gaze and sensibility, and ways of doing and speaking, all of which are different from those of the teachers. And, of course, they bring their knowledge. The participation of film-makers in the classroom means that real life - the world outside the school - comes into the classroom. Here, we stop working in rehearsal mode to join a reality loaded with expectations and demands. In that sense, the triangle between the teacher, the student and the film-maker is very rich and somewhat necessary, not from a hierarchical perspective but due to the multidirectional dynamic it introduces. This teacher-student-film-maker triangle helps dissolve established roles and dynamics; it transforms, and allows each student to find a new place and a new way to relate to others.

Film-makers participating in the discussions highlighted how their presence can also be important in order to demystify the figure of the artist, to let young people live (rather than just hear) the fact that film and creativity require work. All the filmmakers who participated in the 'Transmitting cinema' discussions asserted that, as film-makers, getting involved in educational processes with young people can be a golden opportunity to connect to what is essential in film-making, and with their love of film. These film-makers claimed to rediscover cinema, to put everything they supposedly know from experience to one side in order to rethink it and critique it honestly, and to reconnect with the emotion and primordial desire to make films.

Another point at which the encounter with film-makers can be transformative, which arose from the discussions, is when young people have a chance to talk to the director of a film, to find out about their way of working, to ask with confidence, and to discover their motivations, doubts and hopes. Sometimes, the dialogue is more fruitful when some time has elapsed after the screening, and the students have had time to reflect on the film and prepare for the dialogue. When the conversation takes place in the classroom rather than the cinema, for instance, there is a greater sense of closeness, and the students often perceive it as a good gesture when the film-maker comes to the school.

To conclude, we could argue that while the figure of the film-maker is irreplaceable in generating some experiences and learning, it is also important to remind ourselves that the transmission of creation is not a monopoly of creators. Teachers and mediators are also knowledge producers, rather than being merely disseminators or transmitters.

\section{Cultural institutions}

It is important to communicate that cinephilia is not just for the elite: all young people can be part of it. This not only involves considering the price of admission, but also must involve knocking down some social barriers and prejudices. 'Transmitting cinema' participants felt that it is urgent to reflect on the place of cinema in everyday life, and that the key thing here is to change cultural codes, and our perceptions. 
Sergi Díaz, responsible for neighbourhood facilities for the Institute of Culture of Barcelona, argued that institutions have an obligation to be actively open to young people. In that sense, we ask: How can we act as agents to break barriers, and to translate, instead of being agents who propose? Perhaps we do not need to think so much about what young people want, but we need to give them free rein and even governance. Moving Cinema's Young Programmers moves in that direction (see below: 'Young people's participation in cultural life'). Another related strategic element may be strengthening dialogue between institutions, and encouraging those mediators and agents who work with young people. In that sense, any bridges that can be built between the school and cultural facilities are very relevant.

Another element arising from the discussion was the importance of finding ways to arouse interest without banalizing or infantilizing - a responsibility that also applies to institutions and cultural spaces.

A key challenge is that of communication: How do we reach young people? Through what media? With what languages? Young people speak a language that, relatively speaking, is unknown to us, and from which we are excluded. It was argued that approaches whereby adults try to copy 'youth codes' are usually a grave mistake, and result in young people being driven away. Email does not work, because it is not generally part of how young people communicate. Broadly speaking, discussion participants felt that young people do not see social networks as the place to find that information and that, in this respect, it may be an interesting strategy to bring communication closer to the spaces young people themselves use. For the time being, the most effective medium seems to be personal recommendations (prescriptors), and in that sense it was suggested we might try working with the idea of influencers. Either way, it was felt by many in the discussions that, if young people could feel or take ownership of some cultural spaces, communication could take place there in a more organic way.

Beyond communication, it was also suggested that we must start thinking about creating spaces within institutions so that, besides feeling that the cultural 'offer' belongs to them, young people also feel it is their space. It is key to work from a horizontal perspective, jointly, without thinking in terms of 'offer' or 'service'. True dialogue allows us to discover new channels for teaching and learning. And if we start on this path, if we accept the challenge and the game, we must do it in the awareness that there will always be some contradiction or tension between the institution as a regimented space by definition, and the need for flexibility demanded by processes of participation, translation and accompaniment.

\section{Young people's participation in cultural life}

What do we understand by participation? We associate participation with words such as bond, commitment, implication, autonomy, responsibility, trust, dialogue, critical ability, sharing, being active, and having interests. Even if we do not come up with a definition, it seems in any case that participation always entails choice and personal positioning. At the same time, the personal and the individual are predicated on a strong social component. It is also important to point out that we should look to understand participation at many levels or in many guises. Attendance at cultural events is already a form of participation, and, indeed, various practices and modes of participation are more interrelated than it seems.

A key idea here, arising from the 'Transmitting cinema' discussions, is that cultural participation should be seen as being opposed to consumer logic. We must be able to communicate that culture is something in which we can (and even should) intervene; 
it is not all given - there are things to build and imagine. To do so, we must generate spaces that do not exhaust themselves in the spectacle-experience, but that transcend, and spark discussion and interaction, interpellation and implication. This is particularly decisive for young people, in their first autonomous experiences. Participating in any kind of project is the most direct way to create an emotional impact, a lived experience, and a link that creates an interest in more experiences. How can we create that link? An important element is the value of what is shared, of the sense of belonging - creating groups, so that young people can feel an active part of a collective.

One of the great lines of action for Moving Cinema are the Young Programmers: groups of young people who take responsibility for programming regular screenings in cinemas and neighbourhood facilities, as well as individual screenings at festivals. This second line of work is especially potent from a symbolic point of view, because here young people are not only responsible for their own programming, but they also have a voice in prestigious contexts, and at sessions intended for the general public. Young Programmers select the films, introduce the events, invite experts, facilitate discussion after the screenings, take charge of promotion and so on. It is a long and indepth formative process for the programmers, and it is transformative not only for their relationship with cinema but also for them as individuals. In several cases mentioned during the discussion, a real emancipatory process was seen to take place, with those participating gaining a noticeable sense of confidence and self-esteem.

At the same time, insofar as we want young people's participation to be full, and ideally autonomous, it is important to share with them the framework for the project: conditions, budget and so on. Many of the doubts and questions expressed by the professionals supporting these groups, and by others having similar experiences, centred around questions of autonomy and accompaniment. Many who work with young children suggested that there is often some tension between holding their hand and letting go, between creating spaces for them to manage while also ensuring that those spaces are productive. Another issue regarding autonomy is how to ensure the continuity of the group relative to the entity or institution that promotes the initiative. If we have an age threshold, what happens when participants reach it? Can we expel them from a group they have formed themselves?

Something that has proved especially meaningful in this respect is that young people's participation has sometimes created spaces for intergenerational exchange. As mentioned above, Moving Cinema's Young Programmers have also become recommenders for adults, and this seems a particularly rewarding part of the project.

\section{The bond with cinema auteurs}

Addressing the bond with cinema auteurs, the conference discussion was centred on two issues: the choice of films and film-makers, and the way in which to support reflection about them. Discussion started from the need to make it possible for children and young people to watch in school films that may be far from their habitual or standard fare. This seemed like a necessary move to many involved in the discussion. Important criteria regarding this choice are: (1) the films selected must be films we like ourselves, which we think are good quality and interesting (in general, Moving Cinema and A Bao A Qu work with films by canonical directors); (2) our choice of film in this respect must arouse an interest in students to keep watching films; and (3) chosen films must address us intimately and generate reflection. One of the main tasks of teachers or mediators is precisely this process of selection: our work as programmers and recommenders. The choice of films is therefore key to creating a liking or desire, and to spark interest. 
Here, we share some strategies and ways of generating and accompanying reflection after the screening that arose from the 'Transmitting cinema' discussion sessions:

- To begin with, it is important to avoid clichés. Each screening, with each group, is unique and alive. We must pay close attention to what is really going on among young spectators.

- Regarding the contextualization we might seek to provide for the films or fragments watched, we should try to strike a balance so that the student has enough information and is not lost in the images, without precluding any interpretive path. Either way, when introducing a screening, the most important thing is to arouse interest, to try to connect the students with what they are going to see.

- After the screening, the goal is to open up reflection and to sharpen attention and sensibility. If we want to generate thought, we should try to avoid yes/no questions, as well as those that call for a single answer or where the answers are already known by the facilitator.

- We try to give students the space to speak for themselves as much as possible, making them active participants and trying to valorize their observations. We try to create a dynamic forum for dialogue, so that it is not just a question and answer session between teacher and students, but also among students. We offer our comments as part of peer dialogue, not wishing to impart established knowledge but rather to share in the ongoing analysis. This does not prevent us from participating and contributing knowledge.

- We should avoid rejecting the comments of young people. If we think a comment is wrong, it is better to say 'let's have another look', instead of closing off dialogue with a 'no'.

- It is important for our questions to be concrete. For example: How does the camera move? How could we describe the lighting? What strategy has the filmmaker employed to make this sequence?

- Students gradually acquire the concepts and terms that enable a more exact and adequate expression or description of their analysis.

- In the process of commenting on a screening, taking place over a longer time, it is useful to go beyond the 'like' button way of thinking that seems to have taken hold, not only among young people. That is, it should aspire to move beyond taste, and base that 'like' on argued criteria. This allows students to reflect on what is behind taste, and contributes to their intellectual emancipation.

- Publishing student writing about screenings is an interesting way to value their comments, and it also allows us to be more demanding and rigorous.

- As teachers, film-makers or professionals supporting this discovery of cinema, we must lose the fear of speaking from a first-person perspective and sharing our appreciation and enjoyment.

\section{On watching films in their entirety}

- Participants considered watching films in adequate spaces and conditions to be very important. In this way, they can be appreciated with the required sound and image quality. Ideally, we would go to a cinema, but if there is not one nearby, it is important to seek out the most adequate facility we can find (for example, an auditorium or library). 
- Before the screening, the most important thing is to foster the desire to watch the film. If students are not used to auteur cinema, it is good to set this up, explaining that this kind of cinema may require them to be more active. We might show a fragment from the film we will watch, or a different one, and prompt the students to adopt a point of view that allows them to appreciate the film-maker's choices. We should invite and motivate them to adopt that active viewership position.

- Introductions should be brief, without overloading the screening with previous knowledge. At $\mathrm{CinEd}$, we have designed proposals to foster interest in watching the films through exercises in which students can imagine or foresee something about the film based on a still, the poster, a shot or a quote from the film-maker.

- In this context, it can also be useful to pay attention to the atmosphere and subtle reactions during the screening, in order to pick them up as threads in the follow-up discussion.

\section{On watching fragments in class}

- Participants suggested that it is often a good idea to wait a few minutes after the first screening for students to think individually, to make notes, or to recall a fragment. This way, we can create a personal space and allow everyone to actively think. Silence can also open up a space for emotion, and creates an atmosphere of calm, seriousness and attention.

- After the first screening, it can be important to continue reviewing on the basis of the students' comments.

- It can also often be useful to start the discussion with specifically cinematographic aspects, starting from what we have seen: camera positions, light, colour and so on. (In this respect, it is also often a good idea to indicate beforehand which concrete aspects we will pay attention to.)

- Sometimes, talking about the film-maker after the post-screening discussion provokes a reconsideration of students' first impressions. This can create curiosity about the director, and students might then request watching more of his or her films, or even become interested in a film-making movement.

- What can be done when a screening does not interest the group? It may be preferable to have a session of lightweight analysis or comment, without giving it too much time, and perhaps, if it is important, return to this after a few weeks.

The full list of films that have been shown through the Moving Cinema activities can be seen at www.movingcinema.eu/films.

\section{The experience of creation}

Alain Bergala's book, The Cinema Hypothesis (2016), is acknowledged as a cornerstone for many of the projects that came together during these sessions, including Le Cinéma, cent ans de jeunesse, $O$ primer olhar, and Cinema en curs. As reflected in Bergala's work, many participants in the 'Transmitting cinema' discussions felt strongly that the experience of creation can transform students' relationship to film, both in their creative practice and in their role as spectators. This requires well-contextualized creative practices within a defined framework, and the adoption of rigorous pedagogical and cinematic principles. In this sense, the aims and needs of practical work must thus adapt to logistical possibilities: the creative experience does not necessarily have to involve making a short film! Still, the participants suggested that in order to achieve some 
depth and make the experience of practical work truly meaningful, time is needed. Processes need length and continuity; some discussion participants suggested at least three months, others at least the whole school year. This seemed mainly to be because experimentation, reflection, and the ability to revise are essential to the artistic process, which requires space for trying, exploring, modifying and rethinking. Until one is face to face with a problem or question, one cannot truly be aware of the expressive tools at one's disposal. It can be interesting to foster risk, and a true creative process is, of necessity, an open one, and this openness requires time.

Another point for reflection is the potential tension between process and outcomes. We must prioritize process, while also considering that a good outcome should be the consequence of an enriching process from a pedagogical perspective. In that sense, it is important that students are the authors of every process, from screenwriting to editing, including planning and shooting. Only in this way can they have a global understanding of cinematic creation and become truly responsible for their process. In this context, another relevant aspect is sharing with students the structure, methodology and framework along which the process will develop.

From contributions by Pep Garrido and Ginte Zulyte, participants came to reflect on two methodological aspects essential to Cinema en curs and Moving Cinema: the value of film as an everyday gesture, and the dialogue with film-makers. The first aspect is linked to the basis for both projects: that film be understood not as a spectacle or commodity, but as an art linked to the expression of emotion and thought. Film has a great ability to connect us to what is around us - both in documentary (by capturing spaces, people and occupations from our environment) and in fiction (based on what we know), as well as with regard to its tools. For instance, we think that there is great value in introducing the mobile phone as a creative tool. Pep Garrido highlights the value of letting children and young people discover that art may be about oneself, that it can be intimate and personal, and that it allows us to speak about ourselves, sharing what excites us, what worries us and what surrounds us. Film is not something alien to us but can transform the way we inhabit the world. Thinking, then, about creating a dialogue with film-makers, two aspects become important. First, watching a diverse range of films widens young people's creative horizons, opening up possibilities they could not previously imagine. They become familiar with film's expressive codes and acquire greater sensibility and comprehension of films and film-makers' choices. Second, this places great film-makers as fellow travellers, opening up a live and genuine dialogue, encouraging young people to approach their films to seek help in finding their own paths. The contributions illustrated that the experience of creation allows students from all backgrounds and ages to establish connections with film-makers who they would normally see as very remote from them, by addressing them intimately as creative referents. With the right conditions, prejudices can therefore dissolve into familiarity.

Participants discussed how creative processes can also introduce other important learning elements:

- Students can learn to debate, argue, dialogue, reach consensus and organize; to face uncertainty with confidence; to work collaboratively in teams; to appreciate one's surroundings; to acquire aspects of knowledge and put them into practice; to find creative mechanisms; to recognize one's own and others' work; to acquire self-critical and reflective skills; to reflect on emotions; to value companionship, persistence and hard work. It was largely felt that these are important personal and group transformations. 
- Through film creation processes, students can develop a way of seeing and a voice. They can learn to express themselves and communicate with others. It is not only about acquiring a vocabulary and a technique, but also about an awareness, a sensibility, and an ability to relate to the world and to others.

- Three other important aspects were mentioned: discovery, dealing with the inherent uncertainty of any creative process, and the non-hierarchical relationship between teachers and students.

- The experience of creation can also allow students to go beyond the 'I like'/'I don't like' reaction: it requires them to argue, express themselves and share points of view. This can then lead them to develop the ability to question their own decisions and to be open to others' ideas.

- Students who have experienced creation become aware of the importance of all the professionals who work on a film. Many students point out that they have started paying attention to film credits after this experience.

Another issue that becomes important in this debate concerns the role of adults in these creative processes. First, this aspect of film education is acknowledged as a huge responsibility, precisely insofar as we believe it can be a transformative process in terms of young people's relationships with themselves, others and their surroundings. The role of teachers and film-makers is to support and nurture the processes: we are positioned not as transmitters of a closed knowledge, but as fellow travellers who generate questions and open possibilities. Practical film education therefore becomes about finding a balance between sharing processes in a non-hierarchical way (being another member of the team), while also sharing one's own experience. It is also key to communicate that one has trust in the students, as they are responsible for, and protagonists of, their own learning process. As adults, we do not pretend to have all the answers, and we avoid using terms such as 'correct' or 'incorrect', 'good' or 'bad'. Instead, we try to help develop their questions and find new ones.

\section{Conclusions: Ten proposals}

After two days of lively debate from film, education and cultural professionals from 11 different European countries, we feel we can draw a series of conclusions, which broadly speaking - were shared by all participants. These conclusions constitute ten proposals for our time, emerging out of the Moving Cinema project, and strengthened and inflected through the discussions that occurred as part of the 'Transmitting cinema' conference. They are as follows:

1. Activities during school hours are indispensable to reach young people of diverse social and cultural backgrounds.

2. It is necessary to create bridges between schools, film exhibition spaces and film professionals, to encourage young people to attend film screenings outside school hours.

3. The role of teachers as prescriptors/recommenders is essential at an early stage.

4. Peer recommendations are a powerful means of reaching young people.

5. Creative experience of film-making is a very efficient way to awake an appreciation of, and sensibility for, auteur cinema in young people.

6. Contact or direct work with film-makers is crucial for young people to value and become interested in the work of film professionals. 
7. Teachers frequently feel that they lack resources and tools for both film practice and film viewing with young people; in this respect, digital resources can be hugely meaningful.

8. To awaken interest and love for cinema, digital resources must be complemented with significant meetings in person.

9. Learning about the creation processes of a film significantly enhances an appreciation of its value.

10. In order to foster young people's knowledge of cinema and their analytical ability, analysis of excerpts and entire films must be combined.

\section{Notes on the contributors}

Núria Aidelman is Lecturer in Audiovisual Communication at Pompeu Fabra University, Barcelona. She edited Jean-Luc Godard: Pensar entre imágenes (2010) and she has written articles for a wide range of books and anthologies. These include Plossu Cinéma (2009), Jean-Luc Godard: Documents (2006) and Erice-Kiarostami: Correspondances (2006). She was a film programmer at the Centre of Contemporary Culture of Barcelona between 2003 and 2011. She is a founding member of A Bao A Qu and has been directing it since 2005.

Laia Colell received her Advanced Studies Diploma (DEA) after carrying out scholarship-funded research into the Cahiers of Simone Weil in Paris. She has translated various books on philosophy and cinema, and is a member of the Research Group of the Bibliotheca Mystica et Philosophica Alois M. Haas at Pompeu Fabra University, Barcelona. She is a founding member of A Bao A Qu and has been directing it since 2005.

\section{Filmography}

Estiu 1993 (Summer 1993, ES 2017, Carla Simón)

The 400 Blows (FR 1959, François Truffaut)

Pierrot le fou (FR 1965, Jean-Luc Godard)

\section{References}

Bergala, A. (2016) The Cinema Hypothesis: Teaching cinema in the classroom and beyond. (FilmmuseumSynemaPublikationen 28). Trans. Whittle, M. Vienna: Austrian Film Museum.

Calvino, I. (2016) Six Memos for the Next Millennium. Trans. Brock, G. Boston: Mariner Books.

\section{Papers and presentations}

\section{The school as encounter and springboard}

Núria Aidelman (A Bao A Qu) (2017) La escuela: Encuentro y trampolín. In Catalan. Online. https://vimeo.com/244252183 (accessed 25 July 2018).

Marta Comas (Director of Innovation, Programmes and Education at Consorci d'Educació de Barcelona) (2017) La escuela: Encuentro y trampolín. In Catalan. Online. https://vimeo. com/244316084 (accessed 8 August 2018).

Fanny Figueras (Teacher at Institut Moisès Broggi, Barcelona) (2017) La escuela: Encuentro y trampolín. In Catalan. Online. https://vimeo.com/244317483 (accessed 8 August 2018). 


\section{Young people's participation in cultural life}

Laia Colell (A Bao A Qu) (2017) La participación de los jóvenes en la vida cultural. In Spanish. Online. https://vimeo.com/244321355 (accessed 8 August 2018).

Sergi Díaz (Institut de Cultura de Barcelona) (2017) La participación de los jóvenes en la vida cultural. In Spanish. Online. https://vimeo.com/244318653 (accessed 8 August 2018).

Jordi Ferreiro (Artist) (2017) La participación de los jóvenes en la vida cultural. In Spanish. Online. https://vimeo.com/244319846 (accessed 8 August 2018).

\section{The experience of creation}

Nathalie Bourgeois (La Cinémathèque française - Le Cinéma, cent ans de jeunesse) (2017) La experiencia de la creación. In French. Online. https://vimeo.com/244338748 (accessed 8 August 2018).

Pep Garrido (film-maker - Cinema en curs) (2017) La experiencia de la creación. In Spanish. Online. https://vimeo.com/244340018 (accessed 8 August 2018).

Ginte Zulyte (Meno Avilys) (2017) La experiencia de la creación. In English. Online. https://vimeo. com/244334848 (accessed 8 August 2018).

\section{The bond with cinema auteurs}

Isabelle Bourdon (La Cinémathèque française - Le Cinéma, cent ans de jeunesse) (2017) El vínculo con autores de todos los tiempos. In French. Online. https://vimeo.com/240122246 (accessed 8 August 2018).

Carme Congost (Teacher at Escola de Bordils) (2017) El vínculo con autores de todos los tiempos. In Catalan. Online. https://vimeo.com/240131962 (accessed 8 August 2018).

Teresa Garcia (Os Filhos de Lumière) (2017) El vínculo con autores de todos los tiempos. In French. Online. https://vimeo.com/240460146 (accessed 8 August 2018).

\section{Inside Cinema, Inside 'Estiu 1993': The film's creative process}

Carla Simón (Film-maker and member of the Cinema en curs team) - Original version in Spanish. Online https://vimeo.com/240464704 (accessed 30 August 2018).

\section{Discovering cinema}

Palmira Sabaté and Laia Vallespí (Students at Cinema en curs, Moving Cinema, CinEd) (n.d.) Descobertes del cinema amb Cinema en curs. In Catalan. Online. https://vimeo.com/233708065 (accessed 8 August 2018). 